\title{
A GESTÃO DE SERVIÇOS EM BIBLIOTECAS UNIVERSITÁRIAS: PROPOSTA DE MODELO
}

\author{
Fabiano Couto Corrêa da Silva \\ Claudio Henrique Schons \\ Gregório Jean Varvakis Rados
}

\begin{abstract}
Resumo
Para realizar uma gestão de bibliotecas eficiente é necessário avaliar e monitorar constantemente os indicadores de geração e processamento de seus serviços. Este artigo apresenta uma proposta de modelo de gestão, apoiado em um conjunto de indicadores, através de uma análise da administração de serviços, compreendendo aspectos que suportam a qualidade nas bibliotecas universitárias.
\end{abstract}

\section{Palavras-Chave}

Gestão de bibliotecas; Operações de Serviços; Biblioteca Universitária

\section{INTRODUÇÃO}

Visualizar uma biblioteca universitária como uma organização provedora de serviços, requer a compreensão sobre uma estrutura que abrange: definição de estratégia, valor, marketing, qualidade e gestão da produção. Desta forma, os componentes que integram a organização devem ser gerenciados de maneira a estarem interligados e atuarem em um processo cíclico, onde a definição do escopo de cada item poderá comprometer o sucesso do subseqüente.
Neste contexto, o planejamento estratégico e o conhecimento da capacidade produtiva de uma biblioteca universitária serão determinantes para a geração de resultados positivos, no que diz respeito à satisfação de seus usuários.

Desse modo, compreende-se a necessidade de um modelo de gestão a fim de direcionar as funcionalidades de um centro de informação, contribuindo para que os recursos alocados em cada processo sejam utilizados corretamente, além de permitir aos gestores a tomada de decisão 
direcionada conforme os princípios da biblioteca.

No presente artigo, propõe-se um estudo sobre os indicadores que compõem especificamente a gestão de uma biblioteca universitária, permitindo o entendimento de como esta pode vir a garantir a eficácia e eficiência organizacional, de acordo com os principais conceitos presentes na literatura de administração sobre produtividade e qualidade. Embora o foco desta proposta para a gestão de serviços esteja direcionado para bibliotecas universitárias, o uso das estratégias apontado pode ser aplicado em outras bibliotecas, núcleos de pesquisa e demais centros de informação.

\section{MODELO DE GESTÃO}

A partir do entendimento da biblioteca universitária como um sistema complexo, é necessário definir uma política de gestão capaz de permitir o gerenciamento de sua estrutura funcional da melhor forma. Nesse sentido, a adoção de um modelo de gestão propicia à biblioteca universitária a definição de seu "modus operandi", ou seja, direciona para gerenciar seus processos produtivos utilizando os recursos destinados a realização de suas atividades de forma eficiente e eficaz.

Segundo Pereira e Santos (2001,p.47), “(...) o modelo de gestão consiste no corpo de conhecimento, compreendido como o conjunto de princípios, téc- nicas e explicações, que orientam a concepção e o modo de funcionamento de todos os elementos constituintes de uma organização."

Busca-se então, apresentar uma proposta de modelo de gestão baseando-se essencialmente nos requisitos principais para o exercício de uma biblioteca universitária.

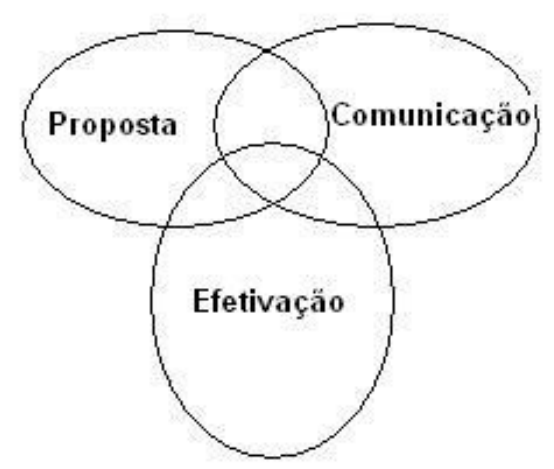

Figura 1 - Funções organizacionais do modelo de gestão proposto

Fonte: Elaboração dos autores

Propomos um modelo de gestão que reúna 3 funções organizacionais desdobradas em 6 elementos: valor da informação, marketing, percepção/satisfação do cliente, ciclo de serviços, gestão da produção e estratégia nos processos.

Conforme apresentado na figura 1 , as funções podem ser identificadas da seguinte maneira:

- Proposta: identificação do valor da informação para o usuário;

- Comunicação: interface capaz de mensurar os níveis de percepção/satisfação do cliente, bem como permitir a vincu- 
lação do fluxo informacional da biblioteca para o usuário e vice-versa (marketing).

- Efetivação:composto por atividades que representam o ciclo de serviço, a geração/produção de demandas informacionais e as estratégias nos processos.

Compreende-se, conforme o modelo de gestão apresentado, que as funções organizacionais estão inter-relacionadas e condicionam ao desdobramento e a integração de cada elemento.

O objetivo principal do modelo de gestão apresentado, é orientar os gestores quanto aos princípios básicos da biblioteca, e propiciar aos mesmos uma tomada de decisão em razão da execução dos processos de gestão, visando garantir a continuidade da biblioteca para que possa atender às exigências e necessidades dos usuários.

Diante do exposto, nos próximos itens são analisados cada um dos elementos constituintes do modelo de gestão.

\section{O VALOR DA INFORMAÇÃO}

Peter Drucker (1998) definiu informação como "dados dotados de relevância e propósito". Quem os dota de tais atributos? As pessoas, é claro. Pessoas transformam dados em informação e, ao contrário dos dados, a informação exige análise. A informação, este conceito difícil de ser definido e mensurado, é o principal componen- te de uma biblioteca universitária. Não é a capa ilustrada de um livro, nem a interface de um sistema operacional para pesquisas que irão atrair o público para uma biblioteca universitária. Por se tratar de biblioteca com estrutura voltada para oferecer acesso à busca informacional de uma elite da sociedade brasileira em termos educacionais, a Biblioteca Universitária necessita gerenciar mais do que o acervo. Precisa como razão de sua existência, gerenciar conteúdos depositados em suas estantes, pois toda vez que um bibliotecário faz catálogos, classifica e distribui o acervo, ele está gerenciando conhecimentos, amplificando o acesso e agregando valor (SILVA, 2005).

Dessa forma, tanto o acervo impresso quanto o gerenciamento virtual das bases de dados realizados pelos bibliotecários e técnicos de uma biblioteca universitária precisam ser administrados de forma que atendam ao perfil da comunidade universitária, se tornando realmente úteis. A Internet e a abertura do mercado editorial facilitam a busca de informações, mas ao mesmo tempo expandem o universo e podemos nos perder (SILVA, 2005). Sob esta perspectiva, o valor da informação torna-se cada vez mais importante neste ambiente de processamento acelerado do conhecimento através da aquisição, tratamento e disseminação da informação aos usuários de uma biblioteca universitária. De acordo 
com Cronin (1990), o valor da informação pode ser classificado como:

-valor de uso: baseia-se na utilização final que se fará com a informação;

-valor de troca: é aquele que o usuário está preparado para pagar e irá variar de acordo com as leis de oferta e demanda, podendo também ser denominado de valor de mercado;

-valor de propriedade: reflete o custo substitutivo de um bem;

-valor de restrição: surge no caso de informação secreta ou de interesse comercial, quando o uso fica restrito apenas a algumas pessoas.

Para oferecer suporte e acesso a diferentes níveis de necessidades informacionais de seus usuários, as bibliotecas universitárias podem estabelecer uma equação de valor, onde:

$$
\begin{aligned}
\text { VALOR }= & \text { Benefícios (ganhos) } \\
& \text { Recursos (Esforços) }
\end{aligned}
$$

Figura 2 - Equação de Valor Para o Cliente Fonte: Rados, Valerim e Blattmam (1999).

Isto representa os benefícios obtidos através de esforços despendidos, ou seja, os resultados alcançados deverão superar os recursos utilizados para determinada ação em uma biblioteca universitária. Como exemplo, utilizando modelo desenvolvido por Rados, Valerim e Blattmam (1999) para demonstrar o valor agregado aos principais serviços desenvolvidos em bibliotecas universitárias, pode-se citar o fluxo do serviço de referência, onde existe um planejamento para o atendimento que envolve treinamento de pessoal, suporte para acesso a informação (software e hardware) e serviços de alerta aos usuários, conforme demonstrado abaixo:

Quadro 1 - Valor agregado aos serviços nas bibliotecas universitárias

\begin{tabular}{|l|l|}
\hline \multicolumn{1}{|c|}{ Serviços de informação } & \multicolumn{1}{|c|}{ Serviços de informação com maior valor agregado } \\
\hline Empréstimo domiciliar & $\begin{array}{l}\text { Possibilidade de renovação e reserva do livro pela Internet, permi- } \\
\text { tindo que o usuário não necessite deslocar-se até a biblioteca. }\end{array}$ \\
\hline Comutação bibliográfica & Viabilizando o envio do material por correio eletrônico. \\
\hline Alerta bibliográfico & $\begin{array}{l}\text { Através do perfil do usuário em banco de dados relacional (perfil do } \\
\text { usuário X bases de dados disponíveis). } \\
\text { Possibilidade de enviar via correio eletrônico conforme informações } \\
\text { de interesse baseadas no perfil. }\end{array}$ \\
\hline Lista de novas aquisições & $\begin{array}{l}\text { Informações via correio eletrônico sobre as novas aquisições, com } \\
\text { base no perfil do usuário. }\end{array}$ \\
\hline Relação de Websites & $\begin{array}{l}\text { Viabilização da compilação dos sites relevantes, ou seja, das fontes } \\
\text { de informação, tendo como base a mudança constante dos endere- } \\
\text { ços existentes na Web. }\end{array}$ \\
\hline Serviço de referência & $\begin{array}{l}\text { Levantamento bibliográfico e suporte para normalização de traba- } \\
\text { Ihos acadêmicos via correio eletrônico }\end{array}$ \\
\hline
\end{tabular}

Fonte: Adaptação de Rados, Valerim e Blattmam (1999). 


\section{MARKETING}

O marketing, visto como um processo estratégico para a divulgação de produtos e serviços, pode significar uma proximidade e troca de informações imprescindíveis para o crescimento de uma biblioteca universitária. Neste sentido, Kotler (1998) define marketing como "a relação de intercâmbio entre duas ou mais partes mediante processos de interação", entendendo-se por processo de interação a troca mútua de informações entre uma parte e outra.

Assim, o marketing tem forte relação com a gestão da produção, visto que é a interface de comunicação entre a organização e o cliente. Conforme Gianesi e Corrêa (1994), nas organizações que prestam serviços, onde estes são consumidos tão logo produzidos, haverá contato direto en- tre o comprador e o prestador de serviço. Dessa forma, identificam a existência de duas funções básicas do marketing para os serviços. A primeira é que a comunicação com o cliente ocorra durante o processo de prestação do serviço ou através da publicidade e propaganda, sendo fundamental para a formação de expectativas dos clientes sobre o serviço prestado.

Da mesma forma que ocorre nas organizações, em uma biblioteca universitária as expectativas dos usuários devem ser atingidas ou superadas pelos serviços oferecidos pela biblioteca, caso contrário os usuários provavelmente irão desenvolver uma imagem negativa do serviço prestado. Dessa forma, é fundamental que a função de marketing esteja alinhada à gestão de produção, pois uma depende da outra para o sucesso de uma biblioteca universitária.

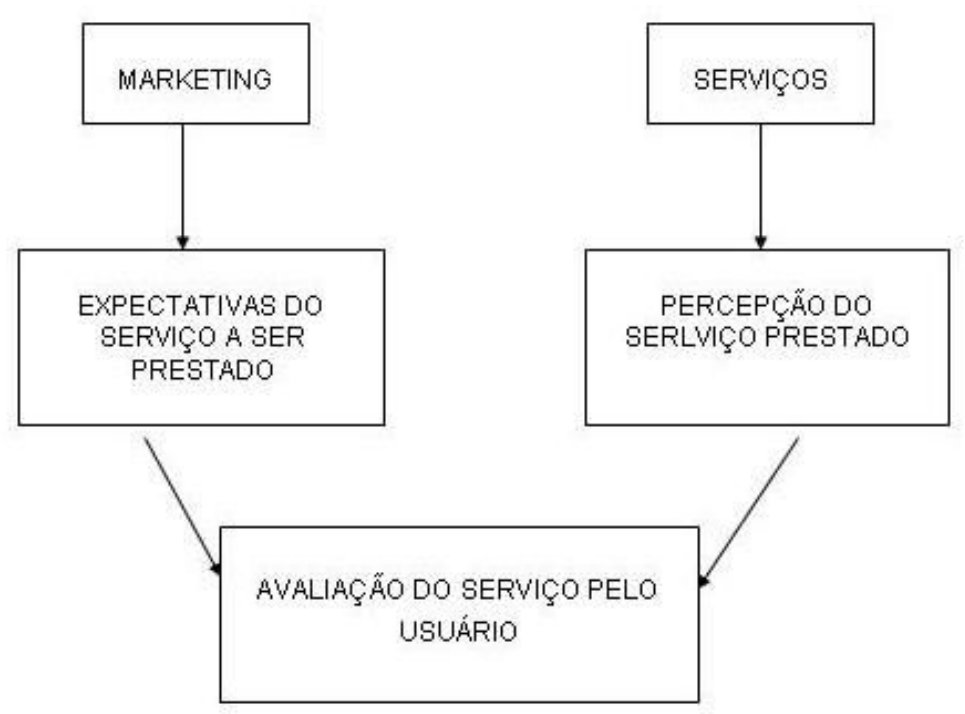

Figura 3 - Integração entre o marketing e os serviços Fonte: Gianesi e Corrêa (1994, p. 38 ).
A segunda função é buscar identificar as necessidades dos usuários para projetar um serviço de acordo com suas expectativas. Gianesi e Corrêa (1994) comentam 
que essa identificação pode ser feita por meio de pesquisas quantitativas ou qualitativas, ou outros métodos capazes de permitir a comunicação direta do cliente com o prestador do serviço como, por exemplo, por caixa de sugestões/reclamações, central de atendimento ao cliente entre outros.

Desse modo, o processo de identificação das necessidades dos clientes está diretamente relacionado com o marketing e a gestão de produção, exigindo que ambas estejam integradas.

Nas bibliotecas universitárias, geralmente podemos identificar dois níveis de serviços: básicos e de valor agregado. Um serviço básico é a leitura, que corresponde a uma das leis de Ranganathan (1967): "um livro para cada leitor". Já os serviços com valor agregado, correspondem aos de disseminação seletiva da informação, levantamento bibliográfico entre outros, ou seja, trata-se de serviços personalizados.

Para divulgar seus serviços, as bibliotecas universitárias utilizam recursos da web, exposição de informativos em murais e contato direto com os usuários. Neste último ponto, oferecem um serviço que merece destaque: as visitas orientadas na biblioteca. Com o propósito de instruir a comunidade acadêmica sobre os procedimentos e requisitos necessários para usufruir seus serviços, algumas bibliotecas universitárias utilizam esta interação entre professores, universitários e a comunidade em geral, para divulgar seu potencial físico e tecnológico e sanar dúvidas de seus usuários. Trata-se de uma oportunidade para realizar o marketing do trabalho exercido pelos funcionários e sua capacidade de atendimento. Conseqüentemente, estas visitas orientadas servem como espaço para o treinamento dos usuários, que passam a compreender o processo de funcionamento da biblioteca. Isto irá proporcionar agilidade do atendimento na prestação de serviços, uma vez que os usuários terão maior conhecimento e autonomia para utilizarem os recursos oferecidos pela biblioteca.

Para oferecer maior qualidade sobre a prestação de serviços, entendemos que as bibliotecas universitárias deveriam compreender um processo de administração, integrando os seguintes elementos: planejamento, organização, treinamento de pessoal, coordenação e financiamento (custos e tempo), onde:

- O planejamento é a definição da metodologia para realizar a administração de marketing;

- A organização compreende a metodologia utilizada para coletar e analisar as informações trazidas pelos usuários;

- O treinamento de pessoal é a capacitação da equipe, de acordo com as necessidades de melhorias apresentadas na 
análise das informações coletadas através das visitas orientadas;

A coordenação e financiamento são os critérios adotados para tomar decisões e acompanhar $\mathrm{o}$ andamento das etapas anteriores, em conformidade com os custos e tempo despendido para realizar a administração de marketing.

\section{PERCEPÇÃO, EXPECTATIVA E} SATISFAÇÃO DOS USUÁRIOS

Por estar em contato direto com o usuário, os atendentes das bibliotecas universitárias podem perceber aspectos importantes sobre o processo de formação da concepção do usuário em relação ao serviço prestado. Assim, a identificação das necessidades e expectativas dos usuários é fundamental. Os gestores das bibliotecas universitárias deveriam buscar entender como ocorre o funcionamento do comportamento dos usuários, pois os processos relativos à prestação do serviço podem ser ajustados e alinhados a fim de permitir um conceito satisfatório para o usuário, ou seja, o usuário irá atribuir identificação de "valor" àquele serviço prestado. Torna-se, então, necessário identificar como ocorrem a percepção, expectativa e satisfação por parte do usuário.

As expectativas estão diretamente relacionadas à experiência, visto que se referem a padrões internos que os clientes utilizam para julgar a qualidade de uma experiência, estando geralmente relacionadas a serviços passados (LOVELOCK e WRIGHT, 2002). De acordo com os autores, existem diversos níveis de expectativas dos usuários, como é demonstrado e descrito abaixo, e ilustrado na figura 4 :

-Serviço desejado: tipo de serviço que os usuários esperam receber.

-Serviço adequado: nível mínimo de serviço que os usuários aceitarão sem ficarem insatisfeitos.

-Serviço previsto: nível de serviço que os clientes efetivamente esperam receber do fornecedor de serviço durante um determinado encontro de serviço.

-Zona de tolerância: grau em que os clientes estão dispostos a aceitar variações na entrega do serviço. 


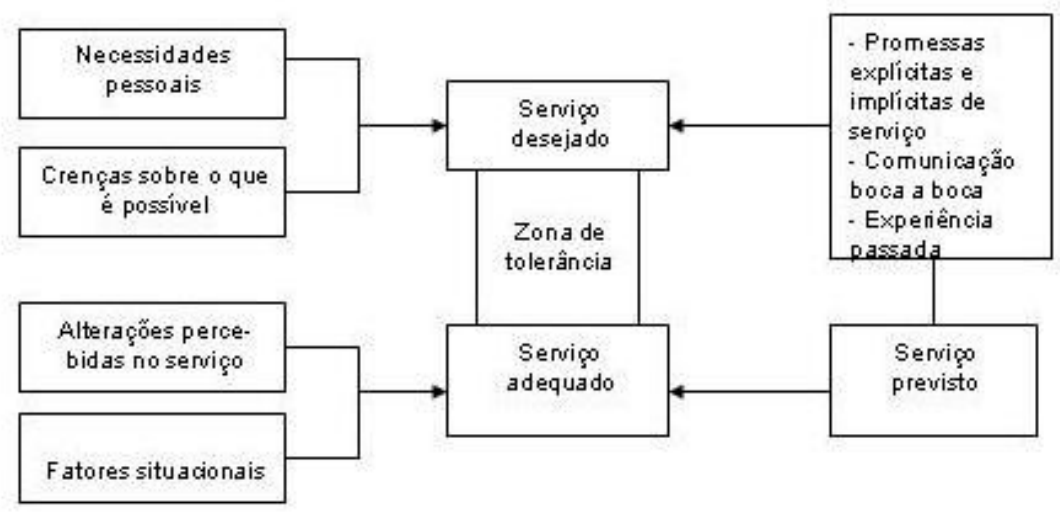

Figura 4 - Níveis de expectativas dos usuários

Fonte: Lovelock e Wright (2002, p. 104).

Existem vários métodos de aborda- neira: primeiro ele formula um juízo sobre o gem da expectativa, sendo que o mais comum de ser aplicado, segundo Marchetti (2001) é o da desconformidade, que mede a satisfação do cliente comparando as expectativas com as percepções. Pode-se observar, nesse relacionamento, que para a geração de uma maior satisfação existem duas possibilidades: o usuário ter expectativa baixa do serviço a ser prestado, ou ter percepção alta referente ao serviço prestado. serviço, ou seja, uma expectativa. Posteriormente, ele emite sua percepção sobre o desempenho do serviço. $O$ resultado se dará com a relação de diminuição da percepção com a expectativa. Lovelock e Wright (2002) afirmam que, quando o cliente tem suas expectativas atendidas ou superadas pela prestação do serviço, então este apresenta qualidade, e logo, o cliente ficará satisfeito. No entanto se a prestação do serviço estiver abaixo das expectativas, o cliente identificará o serviço como sendo de má qualidade, como pode ser observamentalmente pelo usuário da seguinte mado na figura abaixo:

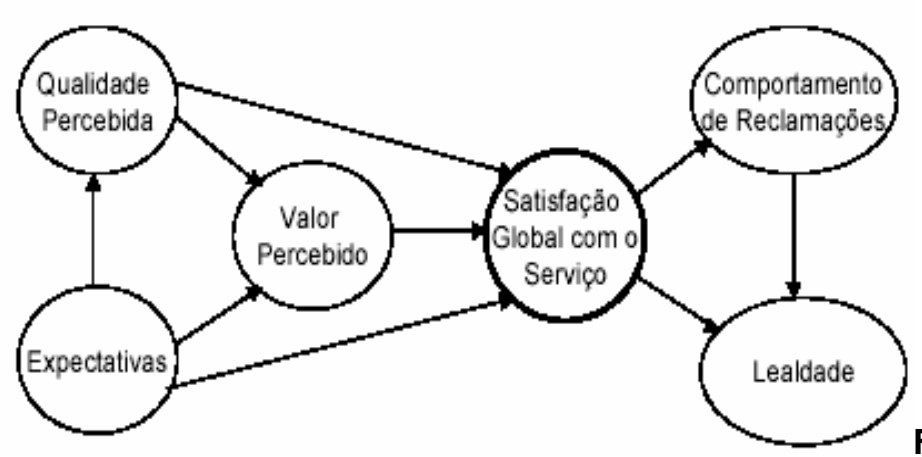

Figura 5 - Modelo de avalia-

ção da satisfação de um comprador baseado em métodos de equações estruturais.

Fonte: Fornell et. al. (1994) 
Na figura 5 é possível verificar que o processo inicia-se com as expectativas, e que após a prestação do serviço ocorre a percepção do usuário (qualidade percebida) e também um valor percebido (relação entre o que o usuário obteve com os esforços realizados). Esses elementos geram a satisfação com o serviço e, caso sejam insuficientes para o usuário, este poderá reclamar ao prestador do serviço, dependendo da contra-resposta do prestador o usuário poderá vir a ser leal ou não.

Conforme Gianesi e Corrêa (1994), o processo de formação de expectativas ocorre devido a quatro fatores, como demonstrado abaixo. Aplicando tais fatores nas bibliotecas universitárias, pode-se afirmar o seguinte:

- Comunicação boca a boca: veteranos e os professores das bibliotecas universitárias.

-Experiência anterior: impressão adquirida pelos usuários, através de serviços prestados anteriormente (confiabilidade, empatia, tangíveis, velocidade do atendimento.)

- Comunicações externas: sinalização dos serviços oferecidos em murais, através do site da das bibliotecas universitárias.

- Necessidades pessoais: suprir necessidades informacionais, seja para o desenvolvimento de atividades acadêmicas ou lazer.

\section{CICLO DE SERVIÇO}

O ciclo de serviço caracteriza o serviço na ótica do usuário, isto é, o conjunto de momentos em que o usuário efetua interação com o serviço e realiza uma análise (julgamento de qualidade do mesmo). Estes julgamentos se dão sempre com base em determinantes de qualidade ou indicadores (FITZSIMMONS, 2000)

Vergueiro (2000) observa que a qualidade dos serviços em bibliotecas universitárias necessita de indicadores que permitam avaliar esses serviços. Nesse sentido, existem formas de mensurar o desempenho, conforme descrito abaixo:

Consistência: expectativa dos usuários sobre um serviço oferecido anteriormente. Por exemplo, ter certeza de que as bibliotecas universitárias possuem um grande acervo.

Competência: habilidades técnicas dos funcionários das bibliotecas universitárias. Por exemplo, o aluno/professor solicita ao bibliotecário de referência um levantamento bibliográfico e o bibliotecário não possui conhecimento sobre as melhores fontes para consulta.

Velocidade do atendimento: percepção de tempo do cliente. Por exemplo, a variação da expectativa dos usuários sobre o tempo previsto para efetuar um empréstimo no horário do intervalo das aulas e o restante do período de atendimento. 
Atendimento: cordialidade e atenção oferecida aos usuários. Por exemplo, a existência de pessoal qualificado para atender ao público em geral.

Atmosfera: é a avaliação do ambiente durante a prestação do serviço. Por exemplo: infra-estrutura adequada para manter uma temperatura agradável; pessoas qualificadas para o uso de uma linguagem e atenção específica ao público universitário.

Flexibilidade: capacidade de mudar rapidamente a operação devido às necessidades dos usuários. Por exemplo: efetuar empréstimos off-line durante uma eventual queda do sistema de gerenciamento do acervo.

Credibilidade: as bibliotecas universitárias devem oferecer amplo acervo; possuindo significativa abrangência sobre diferentes áreas do conhecimento.

Acesso: está numa localização conveniente, uma vez que inserida no campus universitário.

Tangíveis: é a existência de bens facilitadores que ofereçam evidências sobre o serviço prestado. Por exemplo: os funcionários das bibliotecas universitárias possuírem apenas o crachá como identifi- cação de seu vínculo à biblioteca. No entanto, os equipamentos e acervo, são bem sinalizados.De acordo com Cullen (1996), os indicadores antes eram vistos como alvos numéricos ou guias quantitativos para avaliar um serviço específico. Posteriormente, passou a ser apontado como critério de excelência para qualquer aspecto dos serviços e produtos oferecidos aos clientes. Hoje, podemos observar que a gestão da qualidade em serviços de informação é focada no usuário e isso é manifestado no seu desempenho global.

Uma característica de grande importância nos serviços é a sua intangibilidade. Quando o usuário procura o serviço de referência de uma biblioteca universitária e não tem acesso a um produto, o nível de tangibilidade é pequeno. No entanto, ao visualizar o produto, o nível de tangibilidade tende a aumentar. Outro fator importante é que os serviços não podem ser estocados, ou seja, são consumidos (ou utilizados) no momento de sua execução.

Analisando-se o ciclo do serviço de referência de uma biblioteca universitária, é demonstrado o processo de acesso do usuário, em todas suas etapas, conforme figura 6 : 


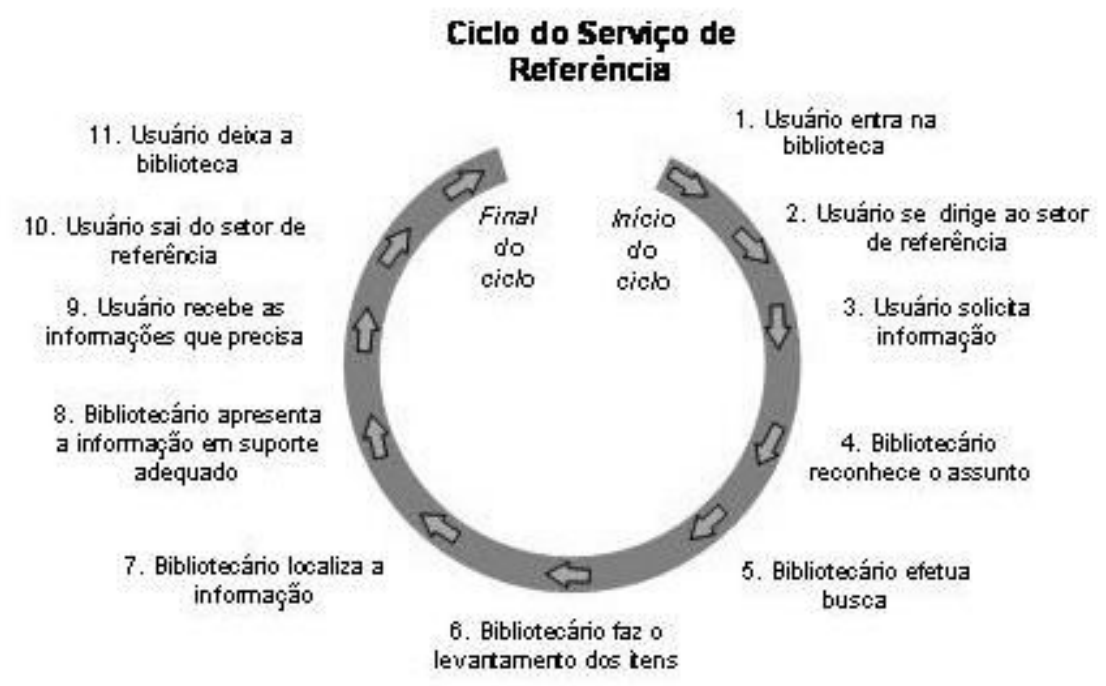

Figura 6 - Ciclo do serviço de referência Fonte: Elaboração dos autores

Durante o processo de um ciclo de em uma biblioteca universitária, é um conserviço, os primeiros e últimos momentos junto de atividades que visa atender os são geralmente os mais críticos para a percepção do usuário, visto que durante esses momentos ele ajusta sua percepção para o restante do ciclo e dificilmente altera sua impressão, ou seja, se no início do ciclo o usuário tem uma percepção negativa, dificilmente esta será alterada. Percebe-se, então, que alguns momentos do ciclo são fundamentais para a percepção do usuário a respeito do serviço prestado, cabendo à coordenação da biblioteca identificar esses momentos, a fim de gerar uma percepção favorável no usuário.

\section{GESTÃO DA PRODUÇÃO}

Basicamente, a função produção realiza os serviços e bens solicitados pelos usuários. Vista como um sistema operacional de fundamental importância estratégica critérios para dar suporte informacional às demandas dos usuários, utilizando os recursos que dispõe. Desse modo, a biblioteca é uma instituição composta por um conjunto de funções responsáveis, desde a implantação até a recuperação da informação e benefício social em que esta poderá se constituir (CAVALCANTE; PINTO, 1996).

Assim, a gestão da produção é a unidade principal em uma organização, independente de esta ser voltada para a produção de bens e/ou serviços. Conforme Gianesi e Corrêa (1994), a gestão da produção provê produtos e serviços aos clientes e está envolvida com diversos subsistemas necessários ao funcionamento da organização como contabilidade e finanças, marketing, $\mathrm{RH}$ e engenharia. 


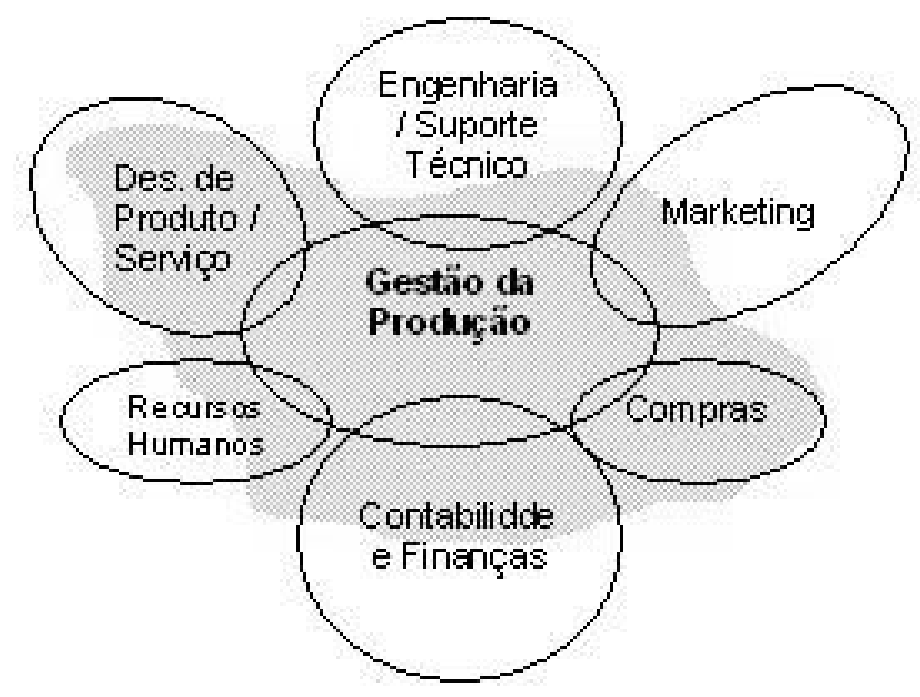

Figura 7 - A gestão da produção e os diversos subsistemas Fonte: adaptado de SLACK et. al (1997, p. 36)

Nesse mesmo contexto, de acordo com a figura 7, Slack (1997) observa que a gestão da produção está centralizada na organização, visto que produz os bens e serviços que são a razão de sua existência, mas nem por isso é necessariamente a mais importante. Todas as organizações possuem outras funções com suas responsabilidades específicas, além da produção, sendo que essas funções são ligadas à função produção por objetivos organizacionais comuns.

A produção dos serviços realizados pelo setor de processamento técnico de uma biblioteca repercute diretamente na qualidade dos serviços prestados aos usuários. Desse modo, a classificação e indexação dos livros determinarão a facilidade com que os usuários poderão resgatar o registro de determinada obra através do sistema de gerenciamento do acervo. Nesse sentido, o trabalho dos bibliotecários de processamento técnico vai além da catalo- gação, classificação e indexação, pois descreve e identifica o conteúdo temático dos documentos (SILVA, 2005)

Para realizar a análise dos documentos que chegam em uma biblioteca universitária, os bibliotecários precisam trabalhar em uma escala produtiva que atenda a demanda que chega até a biblioteca. Para isso, é necessário identificar a área do conhecimento em que o documento será inserido e indexá-lo na base de dados através de termos que facilitem a recuperação da informação pelo usuário, utilizando descritores de uso comum entre a comunidade acadêmica.

Todo o trabalho de cadastramento das obras de uma biblioteca universitária repercute diretamente na facilidade de acesso à informação pelos usuários. Ao fazer a indexação das obras, ele está agregando valor ao título de uma obra, pois através da seleção de descritores, expande as possibilidades de recuperação da infor- 
mação. Por se tratar de um centro de informação onde o fluxo de aquisição de novas obras é muito grande, os bibliotecários das bibliotecas universitárias trabalham continuamente para alimentar a base de dados com novos termos para indexação e, assim, facilitar e agilizar a produção em seu trabalho.

\subsection{A caracterização dos serviços}

De acordo com Gianesi e Corrêa (1994), o gerenciamento da produção de serviços é diferente do gerenciamento da produção de bens, sendo fundamental a identificação das características dos serviços prestados. Segundo os autores, os serviços possuem três características principais:

- São intangíveis;

- Exigem a presença do cliente

- São produzidos e consumidos simultaneamente.

Neste contexto, os principais serviços prestados em uma biblioteca universitária são:Serviço de circulação (acervo geral);

- Condução de pesquisas;

- Serviço de Seleção e Aquisição de informação;

- Serviço de Tratamento da Informação (registro, verificação, catalogação, classificação e triagem do material informacional);
- Serviço de referência (normalização, comutação e levantamento bibliográfico);

- Serviço de periódicos (Revistas técnicas, científicas e informacionais; jornais e relatórios);

- Serviço de coleções especiais (obras raras, teses, dissertações, audiovisual,material cartográfico).

\section{A ESTRATÉGIA UTILIZADA NOS}

\section{PROCESSOS}

Um fator de fundamental importância para o sucesso de qualquer empreendimento, aplicado em uma biblioteca universitária ou não, é a definição de uma estratégia orientada para os objetivos da organização, ou seja, para definir o que não deve ser feito.

Através da definição do planejamento estratégico, a biblioteca irá identificar pontos fortes, pontos fracos, oportunidades e ameaças, de modo que os pontos fortes sejam utilizados, as oportunidades sejam apoiadas, os pontos fracos eliminados e as ameaças neutralizadas. Nesse sentido, o planejamento estratégico direciona a organização em relação ao seu ambiente de atuação conforme suas reais potencialidades (LAS CASAS, 2006).

Um componente principal para a construção de uma estratégia, é a definição do usuário alvo para a biblioteca. Dessa forma, seus esforços são direcionados 
para tentar atender e atingir tais usuários e não o mercado como um todo. Lovelock e Wright (2002) afirmam que assim a organização estará definindo seu foco para um determinado segmento do mercado, processo este que está presente em todas as organizações de serviço bem sucedidas. Os autores definem duas dimensões dife- rentes para o alcance do foco: o foco do mercado, que mede se a organização atinge poucos ou muitos mercados; e o foco no serviço, quando a organização oferece poucos ou muitos serviços, apresentando, conforme quadro abaixo, as quatro estratégicas básicas de foco:

Quadro 2 - Estratégias de foco básicas para as organizações de serviço

\begin{tabular}{|c|c|c|c|}
\hline \multicolumn{4}{|c|}{ Amplitude das ofertas de serviço } \\
\hline \multicolumn{2}{|c|}{} & Estreita & Ampla \\
\hline $\begin{array}{c}\text { Números de } \\
\text { mercados aten- } \\
\text { didos }\end{array}$ & Muitos/Poucos & Foco no serviço & Plenamente focada \\
\cline { 2 - 4 } & Poucos/Muitos & Foco no mercado & Sem foco \\
\hline
\end{tabular}

Fonte: Lovelock e Wright (2002, p. 185)

Conforme demonstrado no quadro 2 , percebe-se que a uma biblioteca universitária pode possuir uma estratégia focada no mercado, ou seja, concentra-se num segmento estreito do mercado através da caracterização de seu público alvo: alunos e professores universitários. Porém, possui uma classe ampla de serviços ofertados, devendo concentrar seus recursos para a prestação desses serviços a seu público alvo. Cabe ressaltar, então, a necessidade da empresa divulgar explicitamente para o mundo externo os serviços orientados para seu público alvo, promovendo assim um filtro e focando os serviços apenas para seu perfil de cliente desejado, evitando possíveis frustrações de clientes que não se adequem ao perfil de publico alvo. No caso de uma biblioteca universitária, a co- locação de avisos na entrada da biblioteca, é uma forma explícita de "filtragem".

Após a definição de quais segmentos do mercado atingir, é necessário estabelecer uma estratégia de serviço para o atingimento ou manutenção de uma posição competitiva. Assim, torna-se necessário estipular que a estratégia seja orientada para permitir uma liderança de serviço. Lovelock e Wright (2002), salientam que quanto mais competitivo o ambiente, mais importantes e significativas são as lideranças de serviço, ou seja, é fundamental distinguir-se dos concorrentes. As estratégias de competição, a fim de se alavancar uma vantagem competitiva na prestação de serviços, segundo Gianesi e Corrêa (1994), não devem ser baseadas apenas na redução dos custos incorridos, mas também 
envolvendo três fatores: na prestação de serviços diferenciados, no aumento da qualidade do serviço prestado e na criação de switching costs (custos de troca).

Dessa forma, conforme figura 8 , a biblioteca universitária deve disponibilizar serviços diferenciados como, por exemplo: atendimento durante $\mathrm{o}$ final de semana, expediente até mais tarde; prestar serviços em que o cliente perceba qualidade e fique satisfeito, como o tempo de atendimento; e nos custos de troca. Cabe salientar que, com a utilização dessas vantagens competitivas, pode-se criar uma barreira a fim de dificultar a entrada de concorrentes. Porter (1986), em seu modelo de análise ambiental, apresenta cinco principais forças competitivas: os possíveis ingressantes em potenciais, os consumidores com seu po- der de barganha, os serviços substitutos, os fornecedores com seu poder de barganha e a rivalidade entre os concorrentes já existentes (figura 9). Nesse sentido, as bibliotecas universitárias desenvolvem suas estratégias levando em consideração as forças competitivas ambientais. Para tal, a identificação de cada elemento torna-se fundamental:

- Entrantes potenciais: bibliotecas setoriais, outras bibliotecas universitárias;

- Fornecedores e Clientes: os fornecedores como editoras, livrarias e distribuidoras de livros devem ser parceiras das bibliotecas universitárias; os clientes são representados pelos alunos, professores e membros da comunidade;

- Serviços substitutos: internet, bibliotecas digitais.

\section{A Vantagem Competitiva Através das Operações}

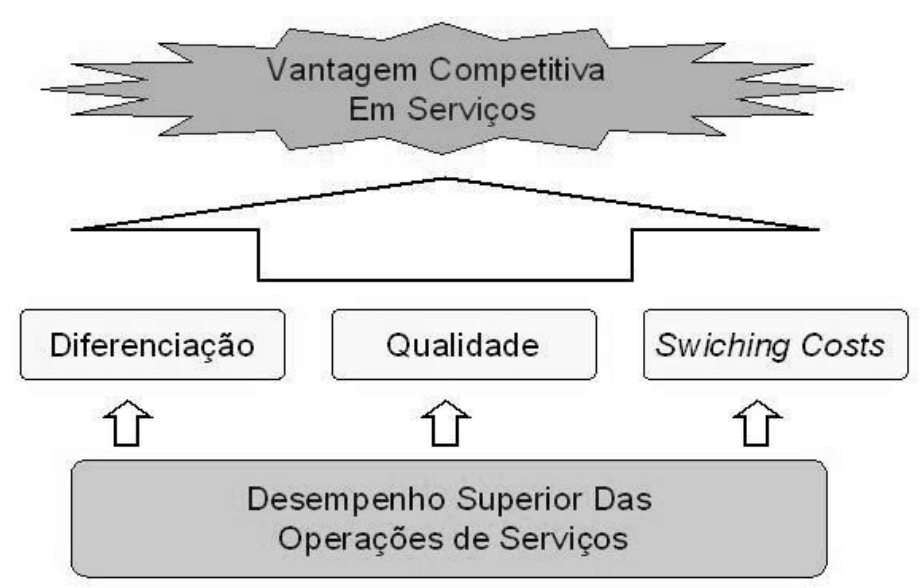

Figura 8 - Estratégias de competição Fonte: Gianesi e Corrêa (1994, p.63) 


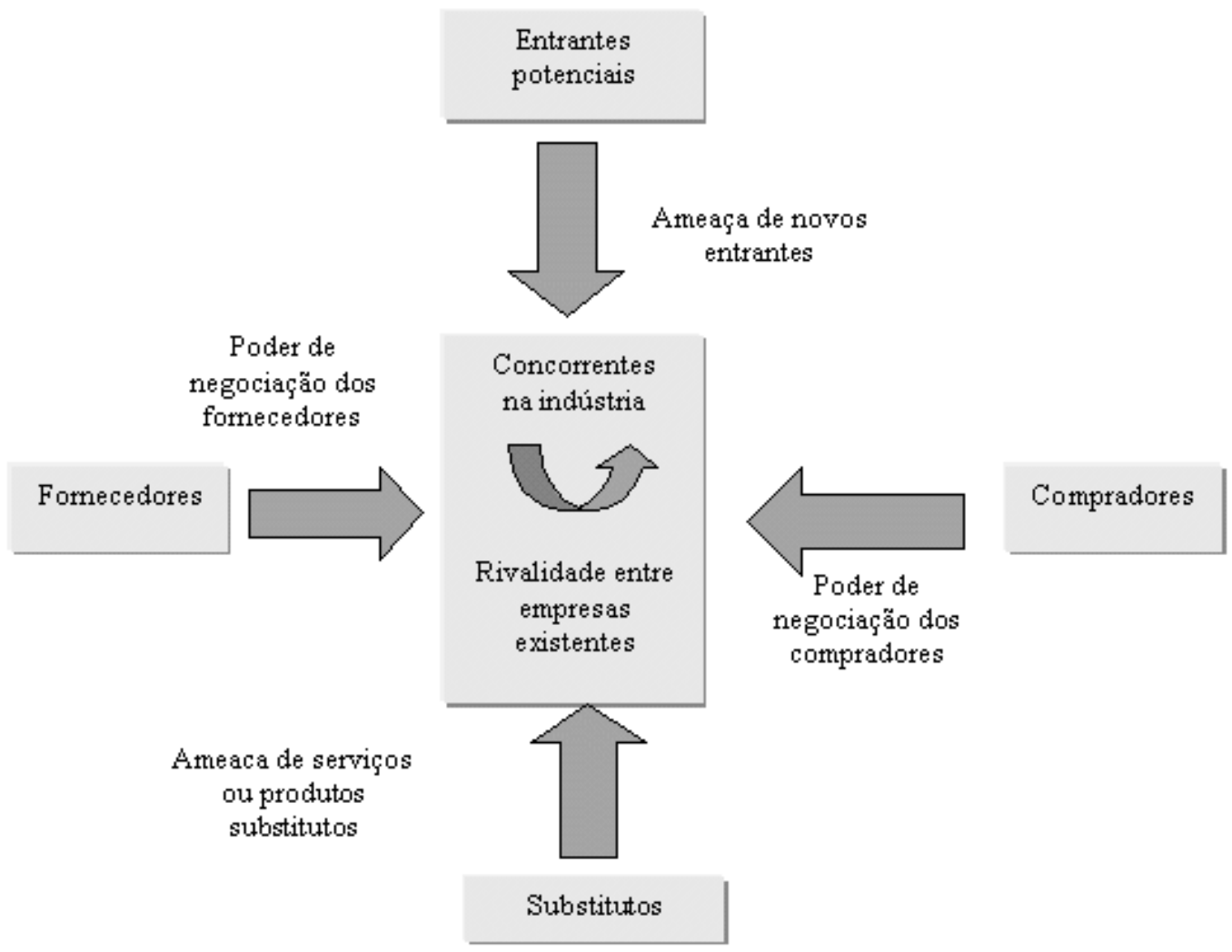

Figura 9 - As cinco forças competitivas.

Fonte: Porter (1986, p.23)

\section{CONSIDERAÇÕES FINAIS}

Os indicadores operacionais de uma biblioteca precisam ser utilizados continuamente como parâmetro para o planejamento e o controle de produção. Assim, deve-se avaliar e dar atenção às questões de uso de processos operacionais como os citados neste trabalho.

Nesse contexto, as bibliotecas universitárias têm utilizado critérios de planejamento que incluem processos internos que proporcionam agilidade no atendimento aos usuários. Sua estratégia operacional, de modo geral, compreende aspectos essenciais para a manutenção da qualidade dos serviços oferecidos aos usuários.
Devido à concorrência cada vez mais acirrada no cenário atual, as bibliotecas universitárias necessitam monitorar e aprimorar constantemente suas políticas de gestão, uma vez que fatores como satisfação dos usuários, qualidade em serviços, gerenciamento eficiente da produção entre outros, são fundamentais para o sucesso e sobrevivência em longo prazo. Para isso, as organizações devem adotar uma política de gestão coerente com seus próprios objetivos, levando em consideração fatores ambientais internos e externos, a fim de permitir que seus serviços agreguem valor ao atendimento, diferenciando-o da concorrência e, conseqüentemente, encantando e fidelizando os usuários. 
Desse modo, salienta-se a necessidade de que os objetivos estejam bem definidos e alinhados com os indicadores apresentados neste trabalho. Este conjunto de ações irá definir a administração dos processos internos das bibliotecas universitárias e, conseqüentemente, unir os requisitos necessários para interligar a estratégia e a disponibilização de seus serviços.

\section{REFERÊNCIAS}

CAVALCANTE, Lídia Eugênia, PINTO, Virgínia Bentes. Gerência da qualidade na biblioteca universitária. In: SEMINÁRIO NACIONAL DE BIBLIOTECAS UNIVERSITÁRIAS, 9, Curitiba, 1996. Anais... Curitiba: SNBU, 1996.

CRONIN, Blaise. Esquemas conceituais e estratégicos para a gerência da informação. Revista da Escola de Biblioteconomia da UFMG, v. 19 , n. 2, p. 195-220, Set 1990.

CULLEN, Gordon. Paisagem urbana. Lisboa: Edições 70. 1996.

DRUCKER, Peter $F$. The coming of the new organization. Harvard Business Review, n. 66, p. 45-53, Jan./Feb. 1998.

FITZSIMMONS, James A.; FITZSIMMONS, Mona J. Administração de serviços: operações, estratégia, e tecnologia da informação.2. ed. Porto Alegre: Bookman, 2000.

FORNELL, Claes. et al. The american customer satisfaction index: Nature, purpose and findings. Journal of Marketing, Chicago, v.58, n. 4, p. 7-18, Oct.,1994.

GIANESI, I.; CORRÊA, H. Administração estratégica de Serviços. São Paulo: Atlas, 1994.
KOTLER, Philip. Fundamentos de mercadotecnia. 4. ed. México: Prentice Hall, 1998.

LAS CASAS, Alexandre Luzzi. Marketing de serviços. 4. ed. São Paulo: Atlas, 2006.

LOVELOCK, Christopher H.; WRIGHT, Lauren. Serviços: marketing e gestão. São Paulo: Saraiva, 2002.

MARCHETTI, Renato; PRADO, Paulo H. M. Um tour pelas medidas de satisfação do consumidor. Revista de Administração de Empresas, Rio de Janeiro v. 41, n. 4, p. 5667, 2001.

PEREIRA, Maria I.; SANTOS, Sílvio A. Modelo de Gestão: uma análise conceitual. São Paulo: Pioneira-Thomson Learning, 2001.

PORTER, Michael E. Estratégia competitiva: técnicas para análise de indústrias e da concorrência. Rio de Janeiro: Campus, 1986.

RADOS, Gregório J. Varvakis, VALERIM, Patrícia, BLATTMANN, Ursula. Valor agregado a serviços e produtos de informação. Informativo CRB 14 / ACB, Florianópolis, v. 9, n. 1, p. 11-12, jan./mar. 1999. Disponível em:

<http://www.geocities.com/ublattmann/pap ers/valor.html> Acesso em: 05 maio 2006.

RANGANATHAN, S. R. The Five Laws of Library Science. Bombay: Asia Publishing House, 1967.

SILVA, Fabiano Couto Corrêa da. Bibliotecários especialistas: guia de especialidade e recursos informacionais. Brasília: Thesaurus, 2005.

SLACK, Nigel. Administração da produção. São Paulo: Atlas, 1997.

SPRENG, R.A., OLSHAVSKY, R.W. A desires congruency model of consumer satisfaction. Journal of Academy of Marketing Science. v.21, n.3, p. 169-177, 1993. 
VERGUEIRO, Waldomiro. Qualidade em serviços de informação. São Paulo: Arte \& Ciência, 2000.

Fabiano Couto Corrêa da Silva Bibliotecário. Mestrando em Ciência da Informação (UFSC) fabianocc@gmail.com

Claudio Henrique Schons Administrador e Analista de sistemas. Mestrando em Ciência da Informação (UFSC) claudioschons@cin.ufsc.br

Gregório Jean Varvakis Rados

Professor Adjunto da Universidade Federal de Santa Catarina. Graduado em Engenharia Mecânica (UFRGS). Mestrado em Engenharia de Produção (UFSC). Doutor em Manufacturing Engineering (Loughborough University) grego@deps.ufsc.br

\section{Title}

The Service Management in University Libraries: a model proposal

\section{Abstract}

To carry out an efficient management of libraries it is necessary to constantly evaluate and to monitor the generation and processing indicators of their services. This paper presents a management model proposal, supported by a set of indicators, through an analysis of services administration, understanding some aspects that support quality in the university libraries.

\section{Keywords}

Libraries Management; Services Operations; University Library.

\section{Título}

La gestión de servicios en bibliotecas universitárias: propuesta de modelo

\section{Resumen}

Para realizar una gestión de bibliotecas eficiente es necesario evaluar y monitorar constantemente los indicadores de la generación y processamento de sus servicios. Este artículo presenta una propuesta de modelo de gestión, apoyando en un conjunto de indicadores, a traves de un análisis de administración de servicios, comprendiendo aspectos que soportan la calidad en las bibliotecas universitárias.

\section{Palabras Clave}

Gerencia de bibliotecas; Operaciones de servicios; Biblioteca universitária

Recebido em: 30.11.2006

Aceito em: 08.01.2007 